\title{
Development The National Institutes of Health Stroke Scale (NIHSS) for Predicting Disability and Functional Outcome to Support Discharge Planning After Ischemic Stroke
}

\section{Agit Putra Pratama, Tejo Tresno, and Sena Wahyu Purwanza}

Faculty of Nursing, Universitas Airlangga, Surabaya, Indonesia

\begin{abstract}
Introduction: A discharged stroke patients with disability from hospital need special identify in order to obtain a meaningful quality of life, to improve the functional status of patient's life quality can be started immediately at admission patient in health sevices. The initial discharge planning was carried out to explore patient's needs during inpatient and discharge with the National Institutes of Health Stroke Scale (NIHSS). NIHSS as a predictor model to discharge stroke patient with disability, need to identify effectivity of it to improve the functional status of patient's life quality with stroke.
\end{abstract}

Methods: Search of journal articles used PECOT framework in the database; Sciencedirect, CINAHL, Elseiver, Sage, Scopus, Ebscohost, and Medline with limitations of publication time is in the last 15 years (2004-2019) by including keywords Natioanal Institutes of Health Stroke Scale, discharge planning, ischemic stroke.

Results: There are 10 journals according specified criteria design that discuss the interventions of discharge planning model patient stroke.

Conclusion: NIHSS can be applied to predicting disability and functional outcome status of patient's life quality with stroke.

\section{ARTICLE HISTORY}

Received: Dec 26, 2019

Accepted: Dec 31, 2019

\section{KEYWORDS}

discharge planning; ischemic stroke; NIHSS

\section{CONTACT}

\section{Agit Putra Pratama}

\section{$\triangle$ agitputra@gmail.com}

$\risingdotseq$ Faculty of Nursing, Universitas

Airlangga, Surabaya, Indonesia

Cite this as: Putra. P. A., Tresno, T., \& Wahyu, P.S. (2019). Development The National Institutes of Health Stroke Scale (NIHSS) for Predicting Disability and Functional Outcome to Support Discharge Planning After Ischemic Stroke Jurnal Ners, 14(3si), 413-417. doi:http://dx.doi.org/10.20473/in.v14i3(si).17220

\section{INTRODUCTION}

Stroke is one of the major causes of disability and mortality all over the world, it given major socioeconomic burden (Al-weshahy, El-sherif, Abd, Selim, \& Heikal, 2017), There are arround 15 million people worldwide experiencing strokes is year (Visvanathan, 2019), this disease is the third largest cause of permanent disability in the world, resulting in significant burdens and costs on the health system (Kushner, Peters, \& Johnson-Greene, 2016). Discharge disposition is a health issue at the participation level and an important health outcome which increasingly gathers attention. For stroke patients, the first and crucial disposition happens after discharge from post-acute inpatient rehabilitation ward. Failure to return home may compromise the quality of lives of stroke patients and families. Understanding its predicting factors helps health professionals to provide counseling and helps policy makers in improving case referral and long term care systems (Hsieh, Chien, Weng, \& Chiang, 2017). Discharge Planning is an important component in hospital care, so it must be given immediately when new patients enter the care facility. It aims to prepare for further treatment, reduce the length of treatment, optimize the use of beds, and improve coordination with home care services. Discharge planning is a process used to decide what patients need to do to improve their health. This process begins when the patient enters and does not end until the patient is discharged, discharge from the hospital does not mean that the patient has fully recovered. This only means that the doctor has determined that the patient's condition is stable enough to treat at home (Kamalakannan et al., 2016). 
The National Institutes of Health Stroke Scale (NIHSS) is a 15-item impairment scale used to measure stroke severity. It was originally developed in 1989 and is now a widely used outcome measure in the recombinant tissue plasminogen activator stroketrials. In the current National Stroke Foundation guidelines, the NIHSS is recommended as a valid tool to assess stroke severity inemergency departments. The original 15-item NIHSS remains the mostwidely accessible, although several versions have been developed(such as the 5-, 8- and 11-item modified NIHSS) and are avail-able in many languages (Kwah \& Diong, 2014). Today, payers and regulators demand reportable data on patient outcomes, and such outcomes must be adjusted for baseline severity: the NIHSS has become the de facto metric for regulatory compliance. The Joint Commission, as part of its certification program for Primary Stroke Centers, now requires an NIHSS score within 12 hours of admission for all stroke patients; this assessment is to be done by a certified examiner (Lyden P, 2017). It is a quantitative measure of stroke-related neurological deficit that has proven intrarater and interrater reliability and has predictive validity for longterm stroke outcome. It includes items to assess level of consciousness, gaze, visual fields, facial palsy, motor strength, ataxia, sensation, language, dysarthria, and extinction or inattention. It is widely used, easy to learn, and can be performed rapidly on admission. Prior studies have found that the NIHSS score could be used to predict disposition (Schlegel, Tanne, Demchuk, Levine, \& Kasner, 2004). Every clinical trial in vascular neurology prevention, acute treatment, recovery requires a severity assessment, and the NIHSS became the gold standard for stroke severity rating after the first successful trial in acute stroke therapy As part of the Trial, detailed and rigorous training/certification procedures were created for the NIHSS that facilitate wider use of the scale outside of research (Lyden et al., 2009). Severity of neurological deficits can be measured by the NIHSS at admission and has previously been identified to independently predict clinical outcomes in stroke patients. NIHSS often changes during the first 24 hours, and the relationship between the neurological examination and long-term functional outcome strengthens after the first few hours and then begins to plateau (Rangaraju, Jovin, Frankel, Schonewille, et al., 2016). The NIHSS' strong ability to predict outcomes after stroke helpsclinicians provide accurate information to patients, set realisticgoals for therapy and plan for discharge. The NIHSS captures bothmotor and non-motor impairments of stroke, and provides a goodoverview of people's deficits (Kwah \& Diong, 2014). This study aim to identify of NIHSS for predict disability and functional outcome to determine the criteria.

\section{MATERIALS AND METHODS}

This systematic review was made with the aim identify of NIHSS for predict disability and functional

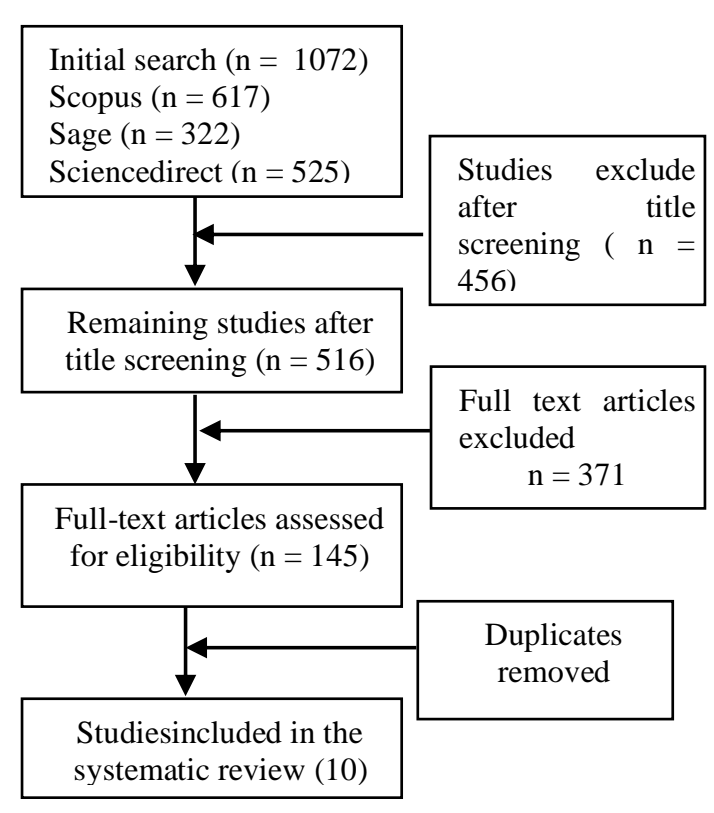

Figure 1 : Prisma scheme

outcome as a determine the criteria of discharge planning after ischemic stroke. The methods used in preparing this systematic review are (1) identification of interventions in the literature, (2) identification of relevant literature based on topics and titles, (3) inclusion and exclusion criteria, (4) obtaining literature in full text form, and (5) analysis of the results of various interventions in the literature.

Literature searches using the PICOT framework in databases such as Scopus, CINAHL, Medline, EBSCOhost, Sciencedirect, Google Scholar and SAGE by including keywords NIHSS, Discharge planning, ischemic stroke, disability and functional outcome. The year limit used is 9 (2004 - 2019) in the last year, with the criteria for implementing to determine of disability and fuctional outcome with NIHSS for discharge planning after ischemic stroke. The PICOT / PECOT framework is: Population : Patient with ischemic stroke trated at hospital, nursing facility and rehabilitation. Intervention : Stroke severity measure with the National Institute Health Stroke Scale related to disability and functional outcome. Outcomes : The scale disability and functional patient when discharge. Based on the determination of keywords according to the topics contained in the PICOT framework, and equipped with Boolean logic methods (Sciencedirect, Scopus, and Sage jurnal) the the keywords in english used are "the National Institute Health Stroke Scale" AND "Discharge Planning” AND “Ischemic Stroke”.

\section{RESULTS}

The inclusion criteria in this study are articles on using NIHSS for criteria disability and functional outcome to discharge patient after ischemic stroke. Design this articles are using cohort study, Retrospective and Quasy experiment. Exclusion 
Table 1. Baseline characteristics of all patients and subgroups of patients at baseline

\begin{tabular}{|c|c|c|c|c|}
\hline Characteristics & $\begin{array}{l}\text { All patients } \\
(\mathrm{n}=200)\end{array}$ & $\begin{array}{l}\text { Unable to } \\
\text { ambulate } \\
(n=114)\end{array}$ & $\begin{array}{l}\text { Unable to move a } \\
\text { cup } \\
(n=51)\end{array}$ & $\begin{array}{c}\text { Unable to feed } \\
\text { oneself } \\
(n=56)\end{array}$ \\
\hline Age $(y r)$, median (IQR) & 78 (65 to 84$)$ & 78 (67 to 83$)$ & 74 (61 to 82$)$ & 75 (61 to 81$)$ \\
\hline Gender, n male (\%) & $98(49)$ & $53(47)$ & $25(49)$ & $27(48)$ \\
\hline Thrombolysis, n (\%) & $19(10)$ & $12(11)$ & $8(16)$ & $9(16)$ \\
\hline \multicolumn{5}{|l|}{ Side of hemiplegia, $n(\%)^{a}$} \\
\hline right & $94(47)$ & $52(46)$ & $22(43)$ & $28(50)$ \\
\hline left & $89(45)$ & $50(44)$ & $26(51)$ & $26(46)$ \\
\hline both & $17(9)$ & $12(10)$ & $3(6)$ & $2(4)$ \\
\hline \multicolumn{5}{|l|}{ Type of stroke, $\mathrm{n}(\%)^{\mathrm{a}}$} \\
\hline ischaemic & $134(67)$ & $78(68)$ & $35(69)$ & $42(75)$ \\
\hline intracerebral haemorrhage & $42(21)$ & $24(21)$ & $14(28)$ & $12(21)$ \\
\hline subarachnoid haemorrhage & $7(4)$ & $1(1)$ & $0(0)$ & $0(0)$ \\
\hline unknown & $17(9)$ & $11(10)$ & $2(3)$ & $2(4)$ \\
\hline Pre-morbid function ( $\mathrm{BI} \leq 95), \mathrm{n}(\%)$ & $47(24)$ & $27(24)$ & $9(18)$ & $11(20)$ \\
\hline \multicolumn{5}{|l|}{ Severity of stroke (NIHSS), n (\%) } \\
\hline mild (0 to 5) & $107(54)^{\mathrm{b}}$ & $49(43)$ & 7 (14) & $12(21)$ \\
\hline moderate (6 to 13$)$ & $59(30)^{b}$ & $43(38)$ & $25(49)$ & $24(43)$ \\
\hline severe (14 to 42$)$ & $33(17)^{\mathrm{b}}$ & $22(19)$ & $19(37)$ & $20(36)$ \\
\hline
\end{tabular}

IQR = Interquartile range, $\mathrm{BI}=$ Barthel Index, NIHSS = National Institutes of Health Stroke Scale. aPercentages do not add to $100 \%$ due to the effects of rounding. 'There was one missing observation for NIHSS, hence the denominator for NIHSS proportions is 199 patients.

Table 2. Univariate Analysis of Predictors for LOS

\begin{tabular}{|c|c|c|c|c|}
\hline Characteristic & No. $(\%)$ & $\begin{array}{l}\text { LOS }>7 \text { days } \\
\text { OR }(95 \% \mathrm{Cl})\end{array}$ & $\begin{array}{c}\text { Median LOS, days } \\
\text { (25th to 75th Percentile) }\end{array}$ & $P$ Value \\
\hline Age & & & & $<0.01$ \\
\hline$<69$ & $72(34)$ & & $5(3-9)$ & \\
\hline$\geq 70$ & $137(66)$ & $2.2(1.2-4.0)$ & $7(4-13)$ & \\
\hline LOI 24 hours after rtPA & & & & $<0.001$ \\
\hline No & $101(47)$ & & $6(4-10)$ & \\
\hline Yes & $115(53)$ & $2.5(1.4-4.4)$ & $8(4-14)$ & \\
\hline Prestroke mRS & & & & 0.01 \\
\hline $0-1$ & $163(80)$ & & $6(4-10)$ & \\
\hline $2-5$ & $41(20)$ & $2.4(1.2-4.9)$ & $11(4-17.5)$ & \\
\hline Baseline NIHSS & & & & $<0.001$ \\
\hline $0-6$ & $29(14)$ & reference & $4(4-5)$ & \\
\hline $7-14$ & $106(51)$ & $4.0(1.4-11.0)$ & $6(3-12)$ & \\
\hline$\geq 15$ & $74(35)$ & $9.4(3.2-27.6)$ & $9(5-18)$ & \\
\hline Cortical involvement & & & & $<0.01$ \\
\hline No & $76(39)$ & & $5.5(3-9)$ & \\
\hline Yes & $121(61)$ & $2.2(1.2-3.9)$ & $7(4-14)$ & \\
\hline New infarction & & & & $<0.001$ \\
\hline No & $42(20)$ & & $4(3-7)$ & \\
\hline Yes & $170(80)$ & $2.8(1.4-5.9)$ & $7(4-14)$ & \\
\hline
\end{tabular}

criteria is an article about giving intervention use NIHSS but not related to discharge planning. The literature search flow in total 1072 records was identified, consist of Scopus $(\mathrm{n}=617)$, Sage Jurnal ( $\mathrm{n}$ $=322)$, Sciencedirect $(n=525)$. Than exclude studies with title screening that remaining $n=516$ articles, we filter remain articles with full-text assessed for eligibility $n=145$, than duplicates removed articles include in the systematic review $\mathrm{n}=10$.

\section{DISCUSSION}

The predictive power of the 24- to 48-hour NIHSS for 1-month mortality and confirmed high predictive power supporting the possibility that 24- to 48-hour NIHSS is likely to have high predictive value for outcomes at later time points as well. Twenty-four- to 48-hour NIHSS accurately predicts 1 -month poor outcome and mortality and represents a clinically valuable prognostic tool for the care of basilar artery occlusion patients.(Rangaraju, Jovin, Frankel, \& Schonewille, 2016). Study conducted by (Schlegel et al., 2004) found that increasing stroke severity, particularly with NIHSS scores greater than 10, increased the likelihood of discharge to rehabilitation or nursing homes instead of to home. This multinational community and academic center-based 
study reinforces the usefulness of the NIHSS score as a predictor of disposition after stroke. The NIHSS score can predict discharge disposition when thrombolysis is used, although possibly with less precision than in patients not given this treatment (Schlegel et al., 2004). More than two-thirds of those who are initially non-ambulant recover independent ambulation, but less than half of those who initially lack upper limb function recover functional use of their upper limbs six months after stroke. Prediction models using age and NIHSS can predict independent ambulation and upper limb function six months after stroke, although these models require external validation. (Kwah, Harvey, Diong, \& Herbert, 2013) the 114 stroke survivors who were unable to ambulate initially, 80 (70\%, 95\% CI 62 to 79) were able to do so at six months. Of the 51 stroke survivors who were unable to move a cup across the table initially, 21 (41\%, 95\% CI 27 to 55) were able to do so at six months. Of the 56 stroke survivors who were unable to feed themselves with a spoonful of liquid initially, 25 (45\%, 95\% CI 31 to 58) were able to do so at six month (Kwah et al., 2013)

Table 2 summarizes predictors of longer stay in the univariate analysis. The overall asymptomatic and symptomatic hemorrhage rates at 36 hours were $10.4 \%$ and $4.1 \%$, respectively. Five patients $(2.3 \%)$ with symptomatic intracranial hemorrhage died. The presence of symptomatic or any kind of bleeding was not associated with longer stay $\left(P_{-} 0.79\right.$ and 0.20 , respectively). Forty patients $(18 \%)$ were treated outside the time window (180 minutes). There was no statistically significant difference in the LOS between those patients treated within or outside 180 minutes of symptom onset (P_0.29).

A total of 118 patients (55\%) had poor outcome (mRS 3 to 5 or death) at 90 days. The frequency of longer stay was significantly higher among patients with poor outcome at 3 months (74\% versus 39.5\%; P_0.001). (Saposnik, Webster, O'Callaghan, \& Hachinski, 2005).

\section{CONCLUSION}

Need to know early on about the severity of ischemic stroke using the NIHSS, as evaluation to provide intervention as early as possible in order to reduce the days of hospitalization of patients ischemic stroke, patients with low NIHSS scale indicates the level readiness to discharge to home so as to reduce maintenance costs by contrast the higher the scala NIHSS as patients are yet to show ability and functional outcome to be discharged. Therefore the NIHSS was able to become one of the reference criteria for the return of patients with ischemic stroke.

\section{REFERENCES}

Al-weshahy, A., El-sherif, R., Abd, K., Selim, A., \& Heikal, A. (2017). The Egyptian Journal of Critical Care Medicine Short term outcome of patients with hyperglycemia and acute stroke.
The Egyptian Journal of Critical Care Medicine, $5(3)$, 93-98. https://doi.org/10.1016/j.ejccm.2017.11.003

Hsieh, S. F., Chien, K. L., Weng, C. H., \& Chiang, Y. P. (2017). Having More Daughters Independently Predicts Home Discharge in Stroke Patients Admitted to Inpatient Rehabilitation Ward. International Journal of Gerontology. https://doi.org/10.1016/j.ijge.2017.07.005

Kamalakannan, S., Gudlavalleti Venkata, M., Prost, A., Natarajan, S., Pant, H., Chitalurri, N., ... Kuper, H. (2016). Rehabilitation Needs of Stroke Survivors After Discharge From Hospital in India. Archives of Physical Medicine and Rehabilitation. https://doi.org/10.1016/j.apmr.2016.02.008

Kwah, L. K., \& Diong, J. (2014). National Institutes of Health Stroke Scale ( NIHSS ). Journal of Physiotherapy, 60(1), 61. https://doi.org/10.1016/j.jphys.2013.12.012

Kwah, L. K., Harvey, L. A., Diong, J., \& Herbert, R. D. (2013). Models containing age and NIHSS predict recovery of ambulation and upper limb function six months after stroke: An observational study. Journal of Physiotherapy. https://doi.org/10.1016/S18369553(13)70183-8

Lyden, P., Raman, R., Liu, L., Emr, M., Warren, M., \& Marler, J. (2009). National institutes of health stroke scale certification is reliable across multiple venues. Stroke, 40(7), 2507-2511. https://doi.org/10.1161/STROKEAHA.108.532 069

Lyden P. (2017). Using the National Institutes of Health Stroke Scale A Cautionary Tale. 513-519. https://doi.org/10.1161/STROKEAHA.116.015 434

Rangaraju, S., Jovin, T. G., Frankel, M., \& Schonewille, W. J. (2016). Neurologic Examination at 24 to 48 Hours Predicts Functional Outcomes in Basilar Artery Occlusion Stroke. 2534-2540. https://doi.org/10.1161/STROKEAHA.116.014 567

Saposnik, G., Webster, F., O'Callaghan, C., \& Hachinski, V. (2005). Optimizing discharge planning: Clinical predictors of longer stay after recombinant tissue plasminogen activator for acute stroke. Stroke, 36(1), 147-150. https://doi.org/10.1161/01.STR.0000150492. 12838.66

Schlegel, D. J., Tanne, D., Demchuk, A. M., Levine, S. R., \& Kasner, S. E. (2004). Prediction of hospital disposition after thrombolysis for acute ischemic stroke using the National Institutes of Health Stroke Scale. Archives of Neurology. https://doi.org/10.1001/archneur.61.7.1061

Visvanathan, V. (2019). Early supported discharge services for people with acute stroke: A Cochrane review summary. International Journal of Nursing Studies. https://doi.org/10.1016/j.ijnurstu.2018.07.00 7 
JURNAL NERS 